\title{
Network Formation of DNA/Polyelectrolyte Fibrous Aggregates Adsorbed at the Water-Air Interface
}

DOI:

10.1021/acs.langmuir.9b02487

\section{Document Version}

Accepted author manuscript

Link to publication record in Manchester Research Explorer

\section{Citation for published version (APA):}

Chirkov, N. S., Akentiev, A. V., Campbell, R. A., Lin, S., Timoshen, K. A., Vlasov, P. S., \& Noskov, B. A. (2019). Network Formation of DNA/Polyelectrolyte Fibrous Aggregates Adsorbed at the Water-Air Interface. Langmuir, 35(43), 13967-13976. https://doi.org/10.1021/acs.langmuir.9b02487

\section{Published in:}

Langmuir

\section{Citing this paper}

Please note that where the full-text provided on Manchester Research Explorer is the Author Accepted Manuscript or Proof version this may differ from the final Published version. If citing, it is advised that you check and use the publisher's definitive version.

\section{General rights}

Copyright and moral rights for the publications made accessible in the Research Explorer are retained by the authors and/or other copyright owners and it is a condition of accessing publications that users recognise and abide by the legal requirements associated with these rights.

\section{Takedown policy}

If you believe that this document breaches copyright please refer to the University of Manchester's Takedown Procedures [http://man.ac.uk/04Y6Bo] or contact uml.scholarlycommunications@manchester.ac.uk providing relevant details, so we can investigate your claim.

\section{OPEN ACCESS}




\title{
Network Formation of DNA/Polyelectrolyte Fibrous Aggregates adsorbed at the Water - Air Interface
}

\author{
N.S. Chirkov ${ }^{1}$, A.V. Akentiev ${ }^{1}$, R.A. Campbell ${ }^{2}$, S.-Y. Lin ${ }^{3}$, K.A. Timoshen ${ }^{1}$, P.S. Vlasov ${ }^{1}$, \\ B.A. Noskov, \\ ${ }^{1}$ Institute of Chemistry, St. Petersburg State University, Universitetsky pr. 26, 198504 \\ St.Petersburg, Russia \\ ${ }^{2}$ Division of Pharmacy and Optometry, Faculty of Biology, Medicine and Health, University of \\ Manchester, Manchester M13 9PT, United Kingdom \\ ${ }^{3}$ National Taiwan University of Science and Technology, Chemical Engineering Department, 43 \\ Keelung Road, Section 4, 106 Taipei, Taiwan \\ *Correspondence: b.noskov@spbu.ru
}

\begin{abstract}
It is discovered that complexes of DNA and hydrophobically modified polyelectrolytes form a rigid network of threadlike or fibrous aggregates at the liquid - gas interface whose morphology can dramatically affect the mechanical properties. While mixed solutions of DNA and poly(N,N-diallylN,N-dimethylammonium chloride) (PDADMAC) exhibit no notable surface activity, the complexes formed from DNA with poly(N,N-diallyl-N-butyl-N-methylammonium chloride) are surface active, in contrast to either of the separate components. Further, complexes of DNA and poly(N,N-diallylN-hexyl-N-methylammonium chloride) (PDAHMAC) with its longer hydrophobic side chains exhibit pronounced surface activity with values of the surface pressures up to $16 \mathrm{mN} / \mathrm{m}$ and dynamic surface elasticity up to $58 \mathrm{mN} / \mathrm{m}$. If the PDAHMAC nitrogen to DNA phosphate molar ratio, $\mathrm{N} / \mathrm{P}$, is between 0.6 and 3 , abrupt compression of the adsorption layer leads unexpectedly to a noticeable decrease of the surface elasticity. Application of imaging techniques reveals that this
\end{abstract}


effect is a consequence of the destruction of a rigid network of threadlike DNA/polyelectrolyte aggregates at the interface. The toroidal aggregates, which are typical for the bulk phase of DNA/PDADMAC solutions in this range of N/P ratios, are not observed in the surface layer. The observed link between the mechanical properties and interfacial morphology of surface active complexes formed from DNA with hydrophobically modified polyelectrolytes indicates that tuning the polyelectrolyte hydrophobicity in these systems may be a means to develop their use in applications ranging from nonviral gene delivery vehicles to conductive nanowires.

\section{Keywords}

Dynamic surface tension; dilatational surface rheology; adsorption kinetics; DNA; polyelectrolytes; poly(N,N-diallyl-N-alkyl-N-methylammonium chloride); polyplexes

\section{Introduction}

Although the interactions of nucleic acids with oppositely charged macromolecules leading to the formation of compact aggregates have been studied for more than forty years, numerous recent reviews show that this subject still attracts great interest, ${ }^{1}$ and some important details of the interactions remain to be elucidated. ${ }^{2-8}$ Investigation of the mechanism of compaction of DNA molecules and their interactions with histones in the course of chromatin formation is one of the key problems of molecular biology. On the other hand, DNA condensation by polycations is also an important step in the gene and drug delivery into intended tissues and cells. Studies of DNA/polyelectrolyte complexes (or polyplexes) have resulted in the creation of nonviral gene delivery vehicles, mimicking viral activities in the delivery of nucleic acids. ${ }^{4-9}$ The extracellular and intracellular aggregation of nucleic acids with other natural polyelectrolytes can be connected with

inflammatory processes in the human body and neurodegenerative diseases. ${ }^{10-12}$ One of the 
hypotheses of the onset of life considers the interaction of individual nucleotides with simple polycations. ${ }^{13}$ An important application of DNA/polyelectrolyte complexes in technology consists of the preparation of conductive nanowires and chemiresistors. ${ }^{14,15}$

In spite of the intensive studies in this subject area, some details of the mechanism of interactions of nucleic acids with oppositely charged polyelectrolytes and of DNA compaction remain unresolved. ${ }^{5,7}$ One of the reasons of the existing difficulties consists of the non-equilibrium nature of investigated systems. DNA/polyelectrolyte nanoaggregates can be kinetically trapped and their morphology depends on the way of mixing of the components. ${ }^{15}$ For example, Pinto et al. showed that the structures of aggregates of DNA and a positively charged protein (protamine) are highly dependent on the method of their preparation. ${ }^{16}$

Most of the authors who have worked on this topic previously considered the interactions of nucleic acids with polyelectrolytes in the bulk phase. To the best of our knowledge, only the groups of James $^{17}$ and Matsumuto ${ }^{18}$ have studied the aggregation of DNA with oppositely charged macromolecules in spread layers at the liquid - gas interface. On the other hand, it is well known that the layers of amphiphilic molecules at fluid interfaces can be considered as physical models of biological membranes, ${ }^{19,20}$ and therefore information on DNA/polyelectrolyte interactions in the surface layer of their solutions can lead to stepwise advances in the understanding of the structure and mechanism of aggregate formation of these substances in real biological systems. Note that adsorption of biomacromolecules at the liquid - fluid interface can influence their conformation, ${ }^{21}$ and lead to the acceleration of the aggregation. ${ }^{22}$

Nowadays Langmuir monolayers of cationic surfactants and lipids are frequently used for studying their coupling to DNA with the aim of the development of DNA-based pharmaceuticals for gene therapy, biosensors and nanodevices. ${ }^{19,23-25}$ This approach, together with the synthesis of new cationic lipids, allows the development of more effective DNA vectors. Studies of DNA/surfactant 
adsorption layers are less frequent and lead sometimes to controversial results probably because of a limited number of suitable experimental techniques. ${ }^{26,27}$ Only recently it has been shown that DNA/surfactant complexes can form a loose network of fibrous aggregates at the liquid - gas interface unlike the more compact aggregates present in the bulk phase. ${ }^{28}$

To the best of our knowledge, adsorption layers of DNA/polyelectrolyte complexes at the liquid gas interface have not been studied to date. The obvious reason is the very low surface activity of complexes formed by DNA and conventional synthetic polyelectrolytes. While the surface properties of their dilute aqueous solutions do not deviate significantly from those of pure water, the use of hydrophobically modified polyelectrolytes gives a possibility to overcome this difficulty through enhancement of the surface activity of resulting complexes.

The present study is devoted to the surface properties of mixed solutions of DNA and three different poly(N,N-diallyl-N-alkyl-N-methylammonium chlorides) (PDAAMAC) that have different alkyl groups, namely poly(N,N-diallyl-N,N-dimethylammonium chloride) (PDADMAC), poly(N,Ndiallyl-N-butyl-N-methylammonium chloride) (PDABMAC) and poly(N,N-diallyl-N-hexyl-Nmethylammonium chloride) (PDAHMAC) (Scheme 1). The use of chlorine counterion instead of, for example, iodide and bromide, is caused by better solubility of the polymers with chlorine and their easier synthesis. It has been shown using atomic force microscopy that complexes of PDADMAC and DNA form toroidal aggregates in aqueous solution if the PDADMAC nitrogen to DNA phosphate molar ratios, N/P, exceeds approximately one. ${ }^{29}$ Further, it has been described how the shape of DNA/surfactant complexes can be modified by tuning the surfactant architecture. ${ }^{30}$ Nevertheless, it has not been resolved to date whether or not the adsorption of DNA/polyelectrolyte aggregates at the water - air interface can lead to changes of their shape like in the case of adsorption of DNA/surfactant aggregates. ${ }^{28}$ 
The scope of this work is for the first time to relate the adsorption and mechanical properties of layers of DNA/polyelectrolyte complexes formed in situ at the liquid - gas interface to the morphology of films transferred onto solid substrates with respect to the hydrophobicity of the polyelectrolyte. Specifically, changes in the dynamic surface tension, surface excess and surface elasticity both during adsorption and after compression of the surface area will be characterized as a function of the bulk composition prior to the imaging of transferred films. The insight provided through linking the mechanical properties of these systems to the interfacial morphology has potential to accelerate the development of hydrophobically modified polyplexes in applications ranging from biomedicine to nanotechnology.

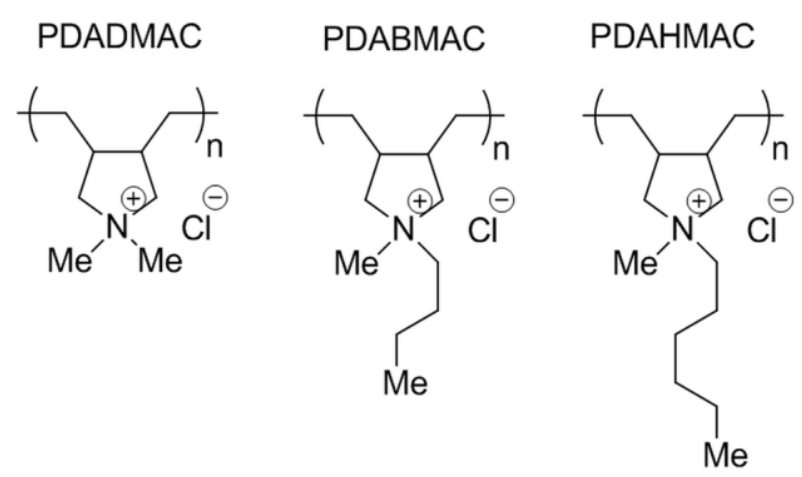

Scheme 1. The chemical structures of the studied cationic polyelectrolytes.

\section{Materials and Methods}

Materials. Calf thymus DNA (fibers, $\mathrm{M}_{\mathrm{w}}=10^{7} \mathrm{Da}, 16 \mathrm{kbp}$ ) containing $6 \%$ sodium salt and PDADMAC (20 wt. \%, $\mathrm{M}_{\mathrm{w}}=100,000-200,000 \mathrm{Da}$ ) were purchased from Sigma-Aldrich and used as supplied. PDABMAC and PDAHMAC were synthesized according to the method described previously. ${ }^{31}$ The polyelectrolytes of this class are stable towards hydrolysis in a wide $\mathrm{pH}$ range. ${ }^{32}$ The purity of polymers was confirmed by NMR ${ }^{1} \mathrm{H}$ spectra (Figs. S1-S6 of the Supporting information). The molecular mass of polymers was determined by Shimadzu LC-20AD chromatograph equipped with the RI detector and TSK gel G5000PWXL-CP column at $30^{\circ} \mathrm{C}$ using 
$0.1 \mathrm{M} \mathrm{NH}_{4} \mathrm{Cl}$ solution in aqueous 2-propanol $(20 \% \mathrm{v} / \mathrm{v})$. Calculations were performed using the data for pullulan standards (Shodex) and the LC Solutions GPC software (Shimadzu). The weight average molecular masses of PDAHMAC and PDABMAC were found to be 630,000 and 250,000 Da respectively with the molecular polydispersity $\mathrm{Mw} / \mathrm{Mn}=1.6$. Sodium chloride $(\mathrm{NaCl})$ was preliminarily heated in a muffle furnace at about $800{ }^{\circ} \mathrm{C}$ for the elimination of organic impurities. Trizma base was purchased from Sigma and used without further purification. All stock solutions were prepared in triply distilled water.

Sample Preparation. DNA fibers were dissolved by weight in $10 \mathrm{mM}$ Tris-HCl buffer solution at pH 7.6 containing $20 \mathrm{mM} \mathrm{NaCl}$ in order to keep the double helix intact. ${ }^{33}$ The stock DNA solution was stored at $4{ }^{\circ} \mathrm{C}$ for no longer than 2 weeks after preparation. The final concentration of DNA was $50 \mu \mathrm{M}$ (in nucleotide units) unless stated otherwise. The concentration of cationic polyelectrolytes varied in the range of $1 \times 10^{-5}-5 \times 10^{-4} \mathrm{M}$. The repeat unit molecular weights considered for the calculations of molar concentration (either in nitrogen units for PDAAMACs or in nucleotide units for DNA), and N/P ratio were 161.5, 203.5, 231.5 and $330 \mathrm{~g} \mathrm{~mol}^{-1}$ for PDADMAC, PDABMAC, PDAHMAC, and DNA, ${ }^{29}$ respectively.

The sample preparation protocol adopted during all the measurements of the dynamic surface properties was as follows. The DNA stock solution was diluted to the desired concentration just before the measurements. The polyelectrolyte stock solution was prepared in $10 \mathrm{mM}$ Tris- $\mathrm{HCl}$ buffer solution at $\mathrm{pH} 7.6$ containing $20 \mathrm{mM} \mathrm{NaCl}$. The solution of DNA of the double required concentration was then slowly (for at least 1.5 hour) dripped to the solution of polyelectrolyte of the double required concentration under constant stirring. The prepared solution was transferred to a Teflon trough, which was cleaned with a chromic mixture and washed carefully with distilled water before use. 
Methods. Surface Tension and Dilatational Surface Elasticity. The surface tension was measured by the Wilhelmy plate method using a rectangular glass plate connected to an electronic microbalance. The glass plate was sandblasted to ensure complete wetting. The plate was cleaned with a freshly prepared chromic acid mixture, washed with distilled water and dried before measurements. Just before the Wilhelmy plate touched the solution, the liquid surface was gently cleaned by a pipet attached to a water pump. The surface tension of each sample was recorded for at least $5 \mathrm{~h}$.

A handmade setup for measurements of the surface dilatational rheological properties by the oscillating barrier method has been described in detail elsewhere. ${ }^{34}$ The Teflon barrier moved back and forth along polished brims of a Langmuir trough, creating periodic expansions/compressions of the liquid surface area. The frequency and amplitude of the oscillations were kept constant and equaled $0.1 \mathrm{~Hz}$ and $3.8 \%$, respectively. The induced surface tension oscillations were recorded by the Wilhelmy plate method. The complex dynamic surface elasticity $\varepsilon$ was then calculated according to the relation $\varepsilon(\omega)=\delta \gamma / \delta \ln \mathrm{A}$, where $\delta \gamma$ and $\delta \mathrm{A}$ are the increments of the surface tension and surface area, respectively. If the phase shift between the oscillations of the surface area and surface tension is known, it is possible to determine the real and imaginary parts of the dynamic surface elasticity, which is a complex quantity.

All the measurements of surface properties were started after purification of the surface using a movable barrier and a pipette connected to a pump. ${ }^{34}$

All of the measurements of the dynamic surface properties were carried out at $20 \pm 1{ }^{\circ} \mathrm{C}$.

Compression isotherms. The compression of the adsorption layer of the investigated solutions was carried out with an ISR instrument (KSV-NIMA, Finland). Two Teflon barriers moved towards each other along the polished brims of a Langmuir through with a constant rate of $20 \mathrm{~mm} / \mathrm{min}$. The surface pressure was determined by the Wilhelmy plate method using a platinum plate. 
Ellipsometry. A Multiskop null ellipsometer (Optrel GBR, Germany) ${ }^{35}$ at a single wavelength of $632.8 \mathrm{~nm}$ was applied to estimate the relative changes of the adsorbed amount at the liquid - gas interface using a fixed compensator $\left(45^{\circ}\right)$ and a two-zone averaging nulling scheme. All the ellipsometric measurements were performed at an angle of incidence of $50^{\circ}$, close to the Brewster angle.

Elliptically polarized light consists of two components with the electric field vectors oscillating parallel and perpendicular to the plane of incidence. The interaction of light with the interface results in changes of the amplitude and phase of these two components. These changes can be characterized by two ellipsometric angles, a relative amplitude change $\psi$, and a relative phase shift $\Delta$, which are related to reflection coefficients $r_{p}$ and $r_{s}$ of the radiation polarized in plane and perpendicular to the plane of incidence, respectively,

$$
\frac{r_{p}}{r_{s}}=\tan (\psi) e^{i \Delta}
$$

The ratio of reflection coefficients depends on the wavelength of the incident light, the angle of incidence, the refractive indexes of the bulk phases, and the refractive index and thickness of the surface film (if present). The exact relation can be obtained within the framework of a specific model of the system under investigation, which makes it possible to calculate the refractive index of the adsorbed layer $\mathrm{n}_{\mathrm{f}}$ and its thickness $\mathrm{d}$ based on the measured $\Delta$ and $\psi$ values. Since the absorption of light at a wavelength of $632.8 \mathrm{~nm}$ is negligible in the system under investigation, only the angle $\Delta$ is considered below. In the model of a thin isotropic layer of uniform density of a single solute between the liquid and gas phases, the difference $\Delta_{\mathrm{s}}$ between the ellipsometric angle $\Delta$ for the investigated solution and that of pure water $\Delta_{0}$ is proportional to the adsorbed amount $\Gamma{ }^{36}$ In the case of two surface-active species, $\Delta_{\mathrm{s}}$ gives only a rough estimate of the total adsorbed amount. 
Atomic Force Microscopy (AFM). The steady state adsorbed DNA/polyelectrolyte films were transferred from the liquid - gas interface onto a freshly cleaved mica plate by the Langmuir-Schäfer technique $^{37}$ and investigated by AFM using NTEGRA Prima and NTEGRA Spectra setups (NT-MDT, Russia) with a tip curvature radius of $10 \mathrm{~nm}$. The mica plate with the transferred DNA/polyelectrolyte layer was stored for at least 2 days in a desiccator at $4{ }^{\circ} \mathrm{C}$. The semicontact regime was used for all of the measurements. NOVA software was used in the course of microscope operation and image analysis.

Dynamic Light Scattering and $\zeta$ Potential. The size and $\zeta$-potential of the DNA/polyelectrolyte complexes in the bulk solution were measured with a Zetasizer ZS Nanoanalyzer (Malvern, U.K.). The instrument employs a He-Ne laser operating at $633 \mathrm{~nm}$ with a $173^{\circ}$ scattering angle. All measurements were carried out at $20 \pm 1{ }^{\circ} \mathrm{C}$.

\section{Results and Discussion}

\section{Adsorption layer formation and kinetics}

Most of the results in the present work, like in our previous study, ${ }^{28}$ were obtained at a DNA concentration of $50 \mu \mathrm{M}$ when the surface properties of its solution are close to those of pure water. The synthetic polyelectrolyte does not display any surface activity at concentrations less than $1 \mathrm{wt}$. $\%,{ }^{38}$ and DNA/PDADMAC polyplexes do not adsorb at the water - air interface. As a result, the surface tension of DNA(50 $\mu \mathrm{M}) / \mathrm{PDADMAC}$ solutions equals the value for water and their surface elasticity is close to zero up to a PDADMAC concentration of $300 \mu \mathrm{M}$ at least (Fig. S7 of the Supporting Information).

At the same time, the surface tension of mixed solutions of poly(N,N-diallyl-N-hexyl-Nmethylammonium chloride) (PDAHMAC) and DNA decreases noticeably even at a polyelectrolyte concentration of $10 \mu \mathrm{M}$ (Fig. 1). In this case, the induction period is a few hours, but it decreases rapidly with the increase of PDAHMAC concentration and is not observed at concentrations higher 
than $20 \mu \mathrm{M}$, when the adsorbed amount corresponding to the surface tension decrease is reached for the times shorter than the period of a single measurement. At lower PDAHMAC concentrations the data exhibit minimal changes in the surface tension, presumably due to very low adsorbed amounts. The static surface tension of DNA(50 $\mu \mathrm{M}) /$ PDAHMAC solutions goes through a minimum of about $57 \mathrm{mN} / \mathrm{m}$ at a polyelectrolyte concentration of approximately $150 \mu \mathrm{M}$ (Fig. 1 inset). At polyelectrolyte concentrations higher than $30 \mu \mathrm{M}$, one can observe two main steps of the surface tension decrease: a fast drop for a few minutes after surface formation and a much slower decrease during more than ten hours after that. If the polyelectrolyte concentration is higher than about 50 $\mu \mathrm{M}$, the first adsorption step leads to a surface tension drop to about $65 \mathrm{mN} / \mathrm{m}$ (Fig. 1). Similar results were obtained for solutions of pure PDAHMAC but the changes of the surface tension were much faster at concentrations lower than about $30 \mu \mathrm{M}$ (Fig. 2), and the pronounced minimum in the plot of surface tension with respect to the bulk PDAHMAC concentration is missing (Fig. 2 inset). The slower changes of the surface tension of $\operatorname{DNA}(50 \mu \mathrm{M}) / \mathrm{PDAHMAC}$ solutions at low polyelectrolyte concentrations $(<30 \mu \mathrm{M})$ as compared with the results for pure polyelectrolyte solutions is an indirect indication of the DNA/PDAHMAC complex formation in the bulk phase of the solution. The concentration of free polyelectrolyte molecules decreases as a result of the complex formation and they adsorb much slower than in the case of pure PDAHMAC solutions of the same concentration. On the other hand, the surface activity of the complexes is lower than that of PDAHMAC in this concentration range and they contribute insignificantly to the surface tension decrease. 


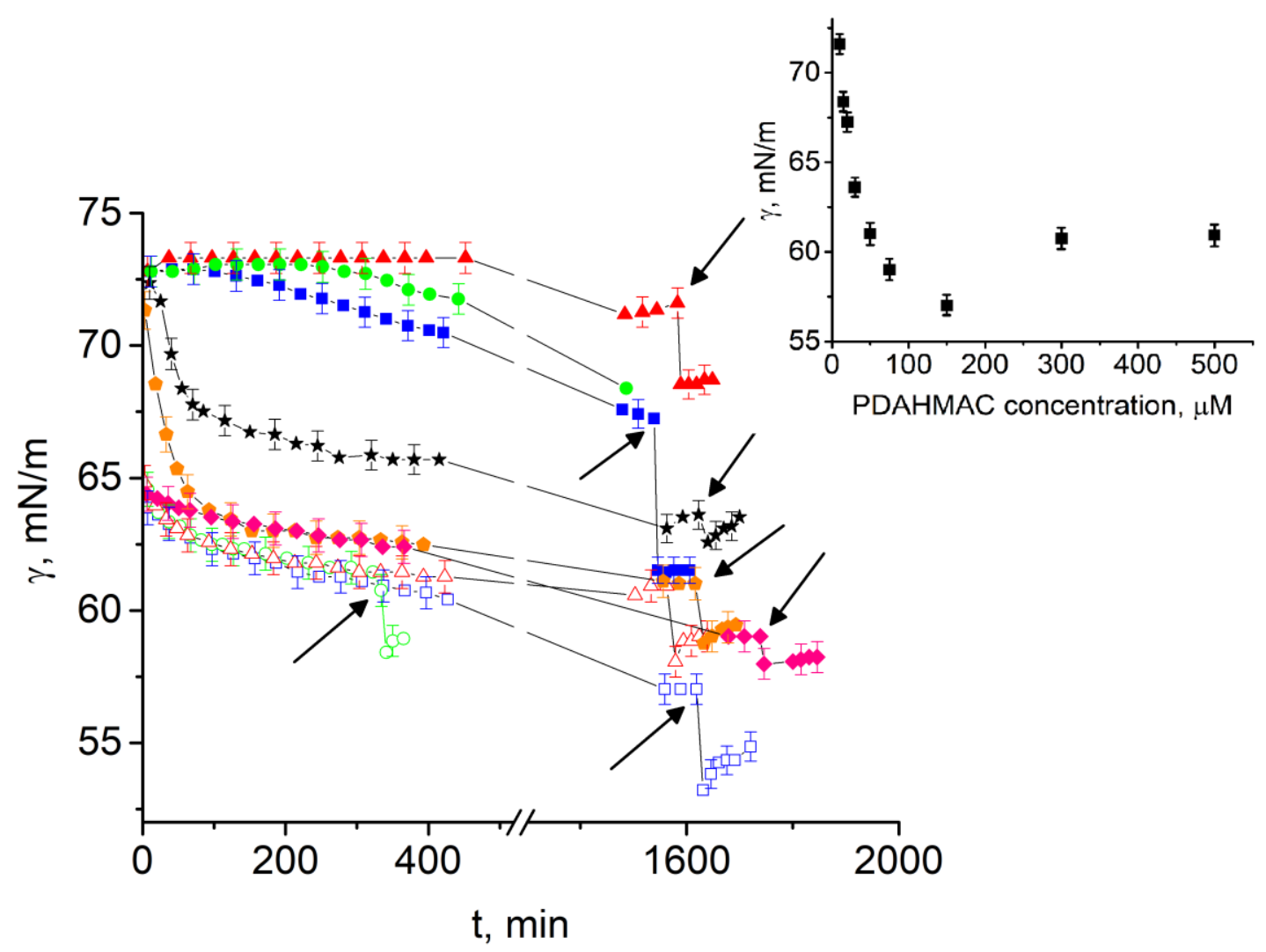

Figure 1. Kinetic dependencies of the surface tension of $\operatorname{DNA}(50 \mu \mathrm{M}) / \mathrm{PDAHMAC}$ solutions at polyelectrolyte concentrations: 10 (red triangles), 15 (green circles), 20 (blue squares), 30 (black stars), 50 (orange pentagons), 75 (pink diamonds), 150 (hollow blue squares), 300 (hollow green circles) and 500 (hollow red triangles) $\mu \mathrm{M}$. Lines are guides for the eye. Arrows indicate the compression of the surface by $40 \%$. The inset represents the dependence of the surface tension before the compression on PDAHMAC concentration. 


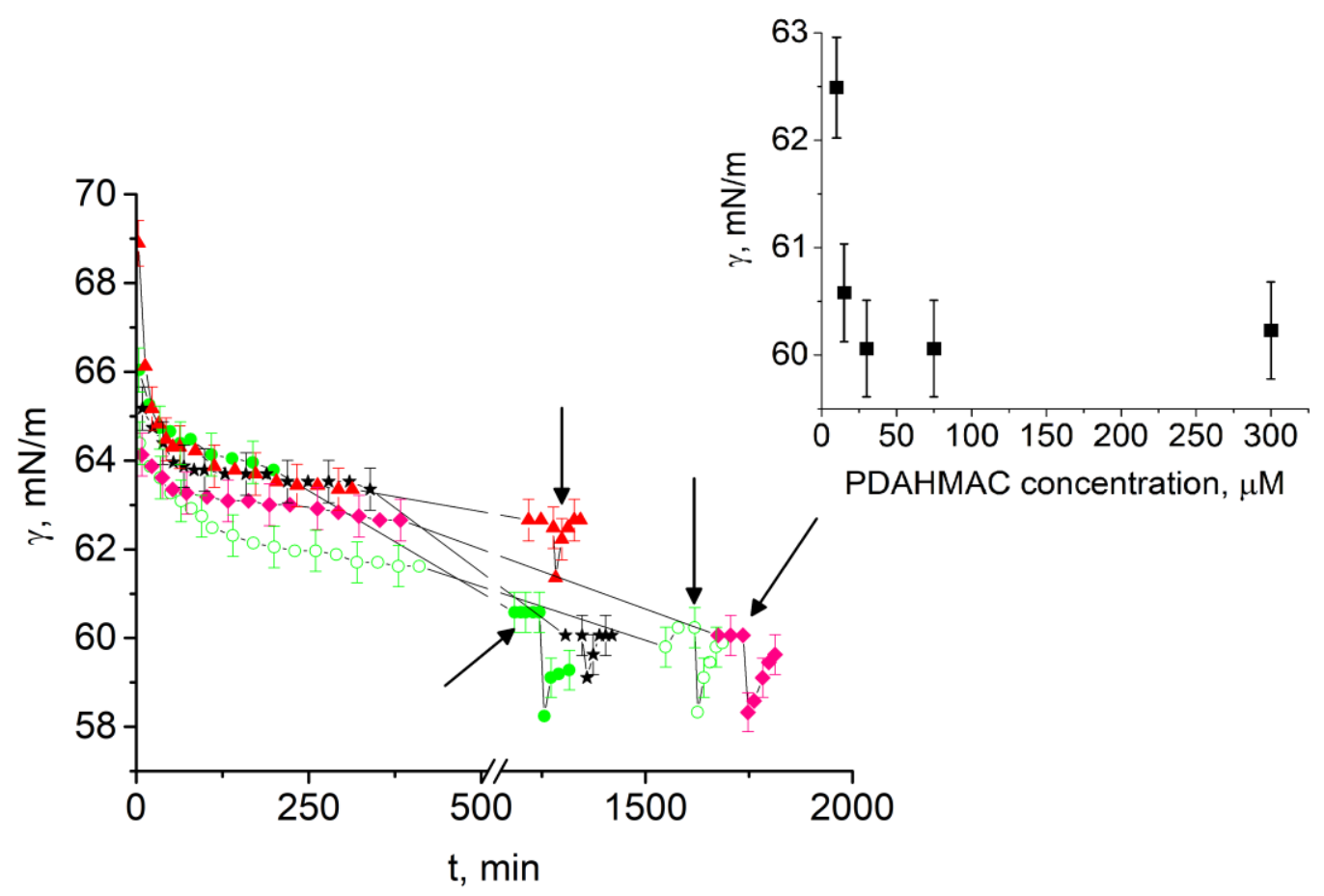

Figure 2. Kinetic dependencies of the surface tension of PDAHMAC solutions at concentrations: 10 (red triangles), 15 (green circles), 30 (black stars), 75 (pink diamonds) and 300 (hollow green circles) $\mu \mathrm{M}$. Lines are guides for the eye. Arrows indicate the compression of the surface by $40 \%$. The inset represents the dependence of the surface tension before the compression on PDAHMAC concentration.

At higher PDAHMAC concentrations - close to $150 \mu \mathrm{M}-$ the surface tension of $\mathrm{DNA}(50$ $\mu \mathrm{M}$ )/PDAHMAC solutions approaches $57 \mathrm{mN} / \mathrm{m}$ and is lower than the minimum value of $\sim 60$ $\mathrm{mN} / \mathrm{m}$ for PDAHMAC solutions (Fig. 1). This result indicates a large number of molecules of the hydrophobically modified polyelectrolyte in the complex and its higher surface activity as compared with PDAHMAC alone. At even higher concentrations $(\geq 300 \mu \mathrm{M})$, the surface tension of both systems almost coincides. A possible explanation consists of the higher surface concentration of PDAHMAC molecules not complexed to DNA in the surface layer of the mixed system. 


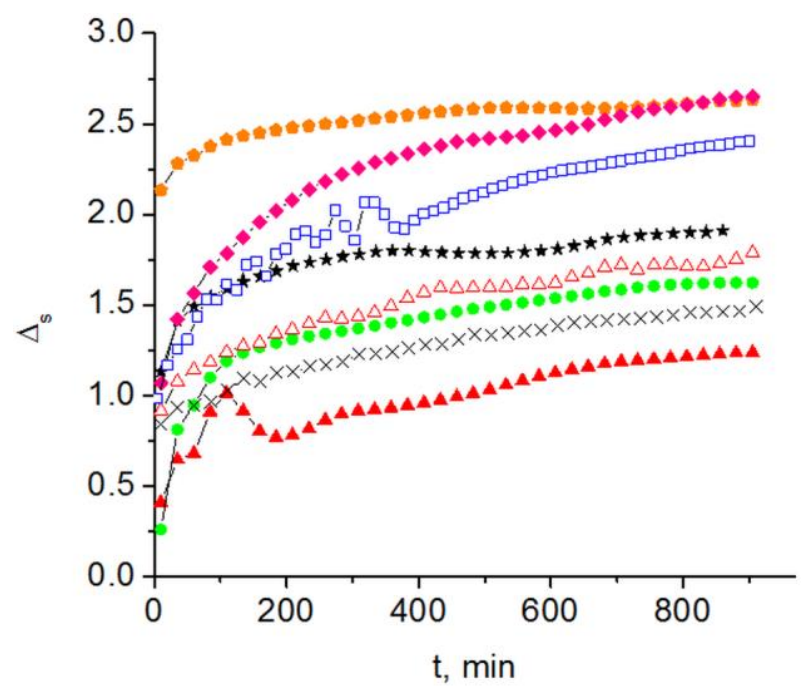

Figure 3. Kinetic dependencies of the ellipsometric angle $\Delta_{\mathrm{s}}$ of mixed DNA $(50 \mu \mathrm{M}) / \mathrm{PDAHMAC}$ solutions at polyelectrolyte concentrations: 10 (red triangles), 15 (green circles), 30 (black stars), 50 (orange pentagons), 75 (pink diamonds), 150 (hollow blue squares) and 500 (hollow red triangles) $\mu \mathrm{M}$. Black crosses correspond to the solution of PDAHMAC with concentration of $300 \mu \mathrm{M}$.

Kinetic dependencies of the ellipsometric angle $\Delta_{\mathrm{s}}$ give additional information about the adsorption kinetics of DNA/PDAHMAC solutions; note that changes of the ellipsometric angle $\Psi$ are close to the error limits in this case and the values are therefore not reported. Although the surface activity of PDAHMAC is lower than that of dodecyltrimethylammonium bromide, $\Delta_{\mathrm{s}}$ reaches higher values for PDAHMAC solutions (Fig. 3 and Fig. 5 of ref. 28) due to its higher refractive index, which is close to the refractive index of DNA (Fig. S8 of the Supporting Information). ${ }^{39}$ Therefore, the kinetic dependencies of $\Delta_{\mathrm{s}}$ in Fig. 3 reflect the total amount of adsorbed DNA and PDAHMAC and cannot be separated into the contributions of these two components. The strong increase of $\Delta_{\mathrm{s}}$ with the increase of PDAHMAC concentration up to about $50 \mu \mathrm{M}$ is mainly a consequence of the corresponding increase of the surface activity of complexes and their higher total adsorbed amount. The decrease of the latter quantity beyond PDAHMAC concentration of $150 \mu \mathrm{M}$ is a result of the 
gradual displacement of DNA/PDAHMAC complexes from the liquid surface by the hydrophobically modified polyelectrolyte. A similar decrease of the surface concentration of complexes occurs in mixed solutions of oppositely charged polyelectrolytes and surfactants as a result of the increase of the total surfactant concentration. ${ }^{40}$ The adsorption rate also depends strongly on the PDAHMAC concentration and is the highest when the concentration is $50 \mu \mathrm{M}$, i.e., $\mathrm{N} / \mathrm{P}=1$ (Table $\mathrm{S} 1$ of the Supporting information), and the total charge of the complexes is close to zero as follows from measurements of zeta potential (Fig. S9 of the Supporting Information). In this case the electrostatic adsorption barrier is negligible but it increases in samples of PDAHMAC concentrations lower and higher than $50 \mu \mathrm{M}$, i.e., deviation of N/P from unity, leading to the deceleration of adsorption (Fig. 3). This behavior is hardly compatible with separate adsorption of DNA and PDAHMAC molecules with the subsequent formation of the complexes at the interface, and can imply that the complexes are mainly adsorbed from the bulk without significant changes of the polyelectrolyte nitrogen to DNA phosphate molar ratio. The ellipsometric signal is observed to fluctuate at the beginning of adsorption, which indicates that the adsorption layer is fluid and macroscopically inhomogeneous. ${ }^{41}$

\section{Adsorption layer mechanical properties}

Unlike monotonic kinetic dependencies of the dynamic surface tension, the corresponding dependencies of the modulus of the dynamic surface elasticity have local maxima for both DNA/PDAHMAC and pure PDAHMAC solutions (Figs. 4 and 5, respectively); note that the imaginary part of the dynamic surface elasticity is close to zero within the error limits for all of the solutions under investigation and the values are therefore not reported. The local maximum of the kinetic dependencies of the dynamic surface elasticity is typical for solutions of amphiphilic nonionic polymers, ${ }^{34,42}$ and can also arise in solutions of polyelectrolytes with an increase of the ionic strength. ${ }^{31,38}$ In these systems the first adsorbed macromolecules have almost flat 
conformations in the surface layer and the surface elasticity increases with the increase of surface concentration. Gradually some loops and tails appear in the surface layer and the surface stresses can be relaxed at the expense of the segment exchange between proximal and distal regions of the surface layers, and as a result, the surface elasticity starts to decrease and goes through a local maximum. An increase of the solution ionic strength in polyelectrolyte solutions leads to the shielding of electrostatic repulsion between charged segments, and as a result to a decrease of the effective rigidity of polymer chains, and to the formation of loops and tails in the distal region of the surface layer. ${ }^{31}$

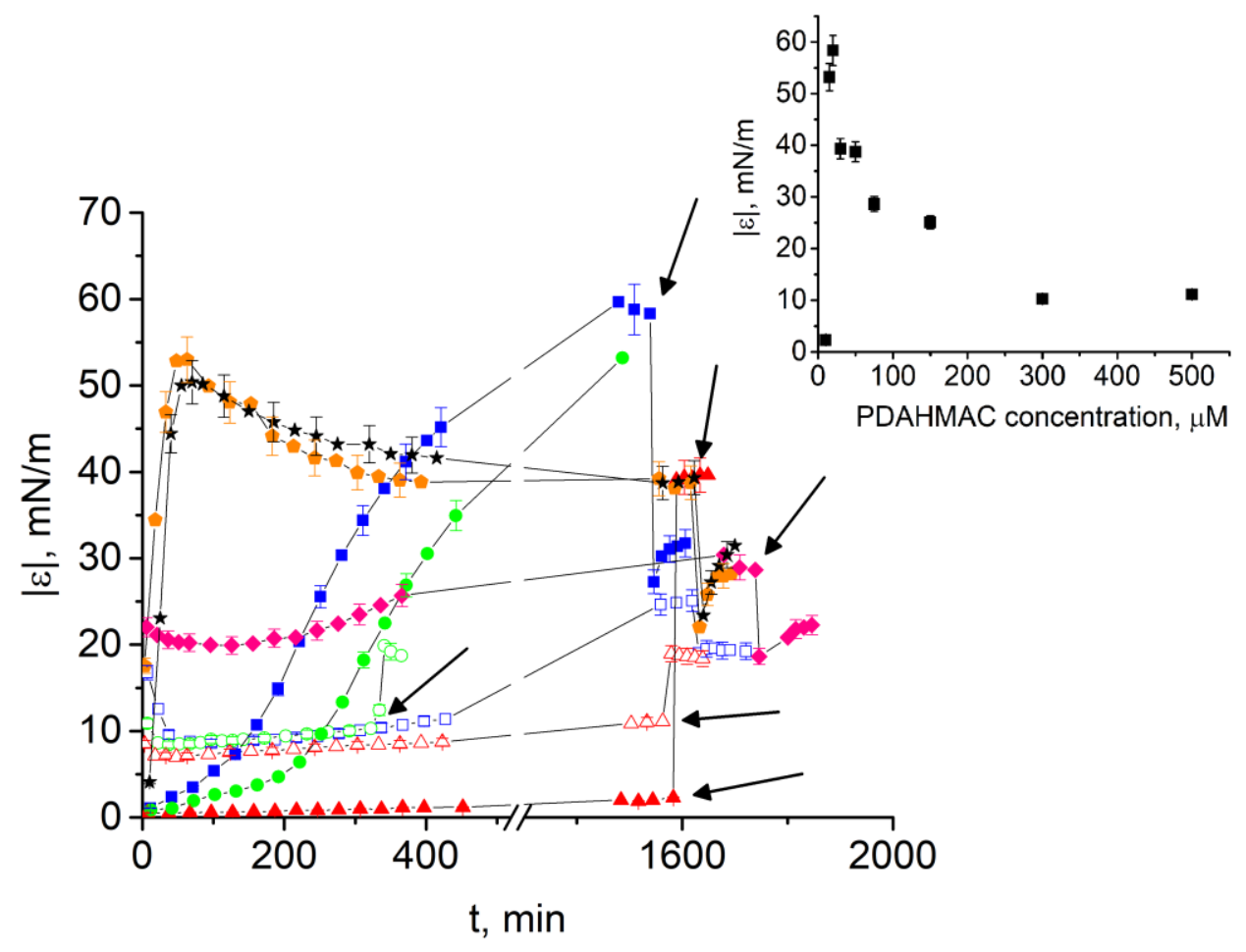

Figure 4. Kinetic dependencies of the dynamic surface elasticity of mixed DNA(50 $\mu \mathrm{M}$ )/PDAHMAC solutions at polyelectrolyte concentrations: 10 (red triangles), 15 (green circles), 20 (blue squares), 30 (black stars), 50 (orange pentagons), 75 (pink diamonds), 150 (hollow blue squares) and 300 (hollow green circles), 500 (hollow red triangles) $\mu \mathrm{M}$. Lines are guides for the eye. Arrows indicate the compression of the surface by $40 \%$. The inset represents the dependence of the dynamic surface elasticity before the compression on PDAHMAC concentration. 
One can observe clear local maxima of the dynamic surface elasticity for DNA(50 $\mu \mathrm{M}) /$ PDAHMAC solutions at PDAHMAC concentrations between approximately 20 and $75 \mu \mathrm{M}$ (Fig. 4) and for pure PDAHMAC solutions at concentrations up to $15 \mu \mathrm{M}$ (Fig. 5). The observed local maxima for the two systems have probably almost the same explanation: a thin and relatively rigid adsorption layer is formed at the beginning of adsorption, which becomes thicker and looser gradually when some segments of the polyelectrolyte participate in matter exchange between the proximal and distal region of the surface layer that then leads to a decrease of the dynamic surface elasticity. At higher concentrations, a close look at the trends in the data suggests that the initial decrease of the dynamic surface elasticity during the first minutes after surface formation may simply mean that a fleeting local maximum is inaccessible by the applied experimental method. Note that the local maximum in Fig. 5 implies also a relatively high flexibility of macromolecules and shows that the hexyl substituent does not influence noticeably the polymer persistence length.

At the same time, other aspects of the kinetic dependencies of the dynamic surface elasticity of DNA $(50 \mu \mathrm{M}) /$ PDAHMAC solutions differ noticeably from the corresponding dependencies of pure PDAHMAC solutions. Firstly, the maximal values in the former case are higher, up to $58 \mathrm{mN} / \mathrm{m}$, as compared with $\sim 38 \mathrm{mN} / \mathrm{m}$ in the latter case. This comparison shows a more rigid structure of the adsorption layer containing DNA even in about half an hour after surface formation. Secondly, for the lower concentrations studied, the dynamic surface elasticity drops to lower values beyond the maximum for solutions of pure PDAHMAC, to values of 9-12 mN/m (Fig. 5 inset) compared with 40-60 mN/m (Fig. 4 inset). This difference points to the stronger interfacial interactions in the adsorption layers involving the DNA/polyelectrolyte complexes. Thirdly, the surface elasticity of DNA(50 $\mu \mathrm{M}) /$ PDAHMAC solutions starts to increase again beyond a local minimum for concentrations higher than $50 \mu \mathrm{M}$ and lower than $300 \mu \mathrm{M}$. The slow increase of the surface 
elasticity at the approach to steady state may indicate the gradual formation of a rigid adsorption layer at the expense of interactions between DNA/PDAHMAC complexes at the interface.

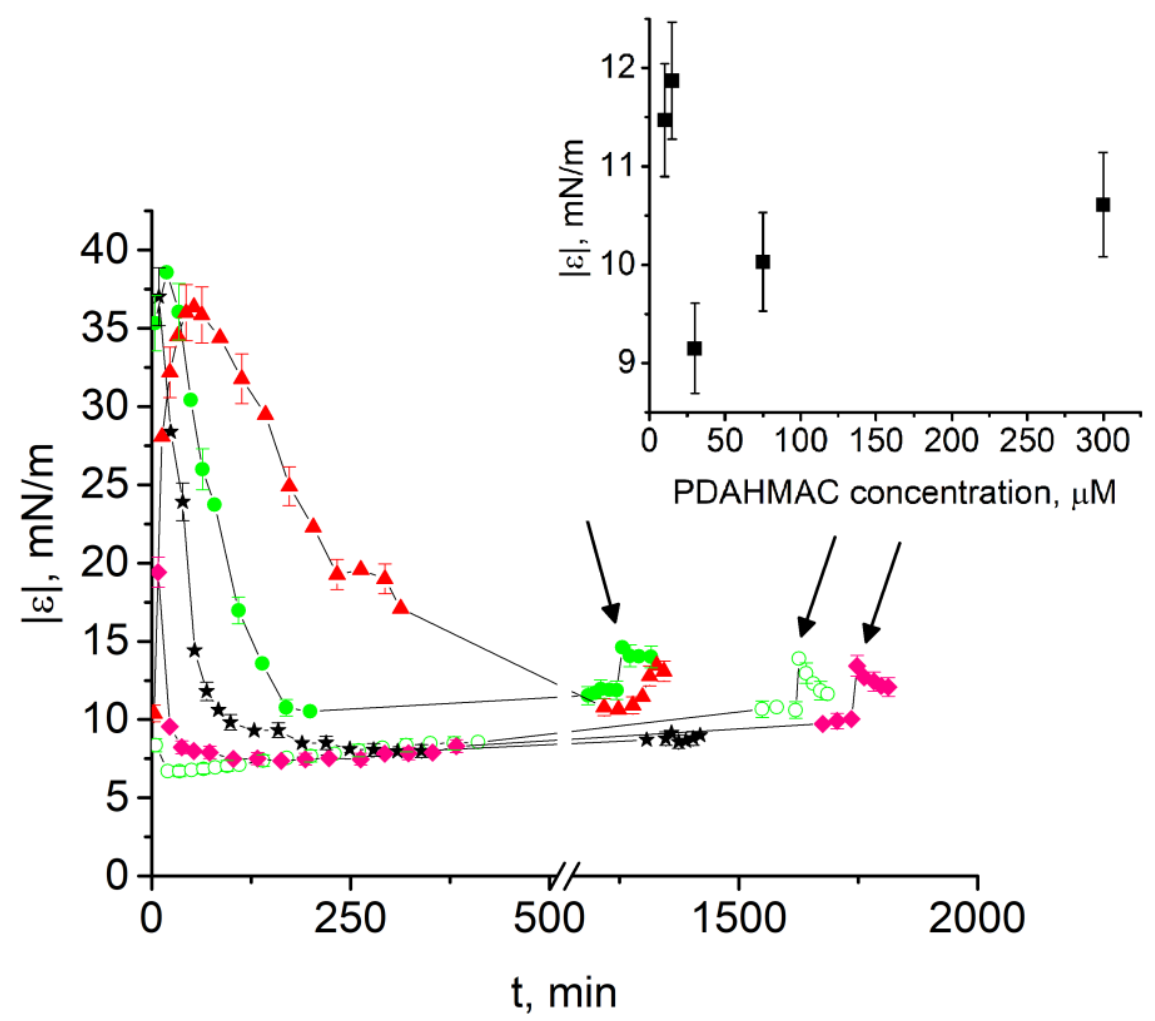

Figure 5. Kinetic dependencies of the dynamic surface elasticity of PDAHMAC solutions at concentrations: 10 (red triangles), 15 (green circles), 30 (black stars), 75 (pink diamonds) and 300 (hollow green circles) $\mu \mathrm{M}$. Lines are guides for the eye. Arrows indicate the compression of the surface by $40 \%$. The inset represents the dependence of the dynamic surface elasticity before the compression on PDAHMAC concentration.

At the same time, there are only weak correlations between the changes of the dynamic surface elasticity (Fig. 4) and of the total adsorbed amount (Fig. 3) for the DNA/PDAHMAC mixed solutions, which can be attributed to differences in the interfacial morphology of the samples. While the dynamic surface elasticity changes strongly with the surface age beyond the maximum at 
concentrations of 30 and $50 \mu \mathrm{M}$, the corresponding changes of $\Delta_{\mathrm{s}}$ at surface ages longer than $20 \mathrm{~min}$ are not significant. On the other hand, strong changes of $\Delta_{\mathrm{s}}$ within $500 \mathrm{~min}$ after the surface formation correspond only to slight changes of the dynamic surface elasticity at concentrations of 75 and $150 \mu \mathrm{M}$. Therefore, modification of the adsorption layer structure and the formation of a rigid network at the interface are accompanied only by a slight increase of the adsorbed amount of the complexes and thereby by slight changes of the surface tension (Fig. 1). These data remind us that surface tension is not a good indicator of structural changes at the interface of complex fluids. As such, in addition to multiple techniques, different experimental methodologies can be applied to provide further insight into the adsorption layer characteristics, as we demonstrate below.

\section{Adsorption layer destruction and relaxation}

The response of the system to an abrupt surface compression gives an additional argument in favor of the formation of a rigid structure. A surface area compression of $40 \%$ of the adsorption layers leads consistently to a decrease of the surface tension due to the increase of the surface concentration (data after the arrows in Figs. 1 and 2). At the same time, the corresponding changes of the dynamic surface elasticity of DNA/PDAHMAC solutions depend on the PDAHMAC concentration (data after the arrows in Fig. 4). At a low concentration of $10 \mu \mathrm{M}$ the surface elasticity increases from almost zero to about $40 \mathrm{mN} / \mathrm{m}$ as a consequence of the surface film compression. At a high concentration of $500 \mu \mathrm{M}$, when one can assume that the adsorption layer consists mostly of PDAHMAC molecules, the dynamic surface elasticity also increases. However, in the intermediate concentration range, the surface elasticity decreases unexpectedly after compression. This observation implies the formation of a rigid network of DNA/PDAHMAC complexes in the surface layer. This network breaks under mechanical perturbations of the layer and the dynamic surface elasticity decreases. The decrease of the dynamic surface elasticity as a 
result of breaking of a fragile structure of the adsorption layer has been also observed recently for solutions of fullerenols ${ }^{43}$ and aqueous dispersions of amphiphilic nanoparticles. ${ }^{44}$

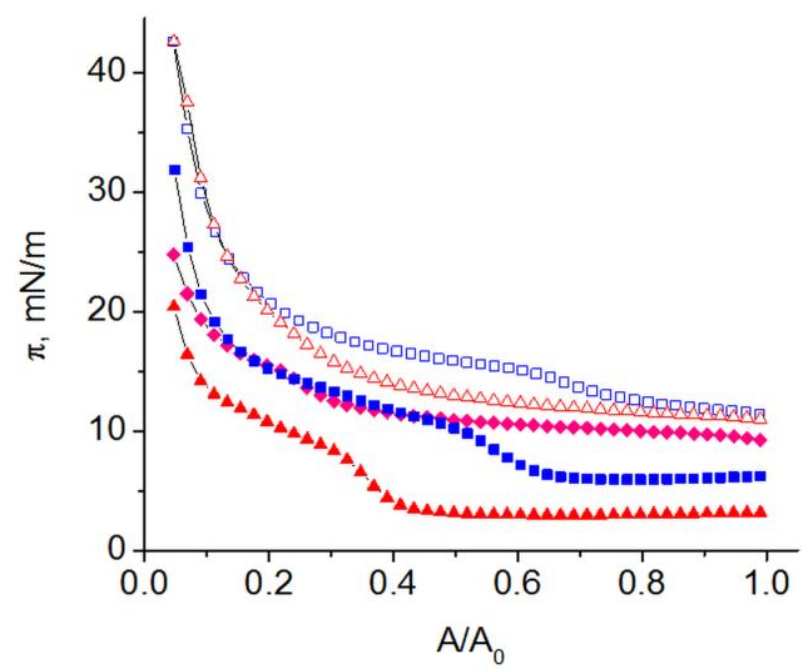

Figure 6. Dependencies of surface pressure on the relative surface area $A / A_{0}$ for mixed DNA(50 $\mu \mathrm{M}) /$ PDAHMAC solutions at polyelectrolyte concentrations: 10 (red triangles), 20 (blue squares), 75 (pink diamonds), 150 (hollow blue squares) and 500 (hollow red triangles) $\mu \mathrm{M}$.

Compressions of DNA/PDAHMAC adsorption layers prepared on a Langmuir trough were then performed that were more extensive (twentyfold vs. $40 \%$ of the surface area) and more gradual (> $50 \mathrm{~min}^{-1}$ vs. $0.1-1.3 \mathrm{~min}^{-1}$ rate of relative change of the surface area) than above: this different methodology was adopted in order to trace the main steps of the layer destruction (Fig. 6 cf. Figs. 1 and 4). The surface pressure almost does not change at the beginning of compression indicating that the complexes are relatively flexible and/or they can fill in some empty area at the solution - air interface. The extent of compression without changes of the surface pressure decreases with an increase of PDAHMAC concentration and disappears completely at a concentration of $150 \mu \mathrm{M}$. Continuation of the compression after this point results in a gradual increase of the surface pressure corresponding to the further compaction of the adsorption layer and an increase of the number of 
hydrophobic groups in the proximal region of the surface layer. A change of the slope of the compression isotherm is then due to a possible transition between two surface phases, which can be attributed to collapse of the layer, and presumably the formation of thicker interfacial structures. Nevertheless, a direct structural characterization using neutron reflectometry for example, which is outside the scope of the present work, would be required in order to validate this inference. The slope gradually increases after that and the surface pressure finally reaches high values, up to 45 $\mathrm{mN} / \mathrm{m}$ at a concentration of $150 \mu \mathrm{M}$. The last compression step may correspond to the formation of a compact multilayer structure at the interface that is unstable, because the surface pressure starts to decrease when the compression stops (Fig. 7).

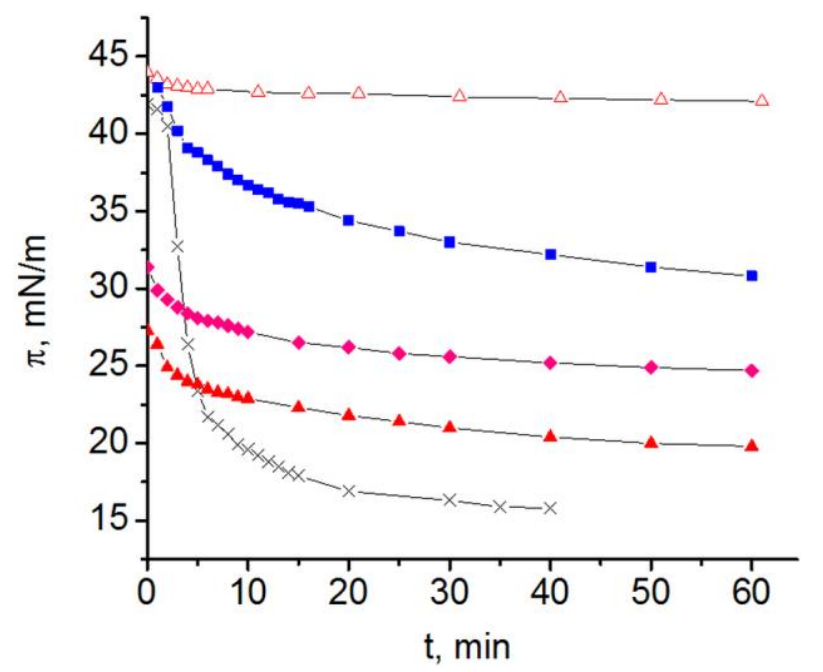

Figure 7. Relaxation of the surface pressure after compression of the surface of mixed DNA(50 $\mu \mathrm{M}$ )/PDAHMAC solutions at polyelectrolyte concentrations: 10 (red triangles), 20 (blue squares), 75 (pink diamonds) and 500 (hollow red triangles) $\mu \mathrm{M}$. Black crosses correspond to the solution of PDAHMAC with concentration of $300 \mu \mathrm{M}$ in the absence of DNA.

The presence of DNA in the adsorption layer influences strongly the time of the surface tension relaxation. If the layer contains only PDAHMAC, the surface pressure returns to the value before 
compression after about half an hour (black crosses in Fig. 7). In the DNA (50 $\mu \mathrm{M}) /$ PDAHMAC solutions, the relaxation rate is an order of magnitude slower. It is noteworthy that the slowest relaxation rate is for a PDAHMAC concentration of $500 \mu \mathrm{M}$, which implies that the adsorption layer contains some DNA even at high PDAHMAC concentrations. In other words, the surface concentration of DNA in the adsorption layer increases upon compression, and the resulting formation of a stable film results in a slower rate of mechanical relaxation.

Here the information presented above is considered together in order to link the adsorption layers properties of the DNA/PDAHMAC system to the N/P ratio of complexes in the bulk. At low polyelectrolyte concentrations $(\mathrm{N} / \mathrm{P}$ ratios $\leq 0.2)$, the ellipsometric measurements show that the total adsorbed amount is close to the value corresponding to pure polyelectrolyte solutions, and the interfacial properties are determined primarily by the polyelectrolyte (Fig. 3). Nevertheless, strong compression of the adsorption layer and the subsequent relaxation of the surface pressure indicate also the presence of complexes at the liquid - gas interface that do not form a continuous network prior to surface area compression (Figs. 6 and 7). The adsorption rate decreases faster than that of pure PDAHMAC solutions, which can be attributed to the presence of an electrostatic adsorption barrier (Fig. 3). At higher N/P ratios, a decrease of the charge of the complexes results in acceleration of the adsorption and an increase of the total adsorbed amount (Fig. 3). In this case the dynamic surface elasticity indicates the formation of a relatively rigid network of DNA/polyelectrolyte complexes at the interface (Fig. 4). The first adsorption step for about 30 minutes consists of the fast adsorption of complexes presumably with some polyelectrolyte molecules, while their spreading and linking with other adsorbed complexes in the course of the second adsorption step leads to the slow network formation and to the corresponding increase of the dynamic surface elasticity beyond a local minimum (Figs. 1 and 4). The highest adsorption rate is observed at N/P ratios $\sim 1$ (Fig. 3) when the absolute value of the complex charge is minimal. At 
higher N/P ratios, the complexes become positively charged and the adsorption rate decreases (Fig. 3). Nevertheless, a rigid network of DNA/polyelectrolyte complexes exists at the interface even at $\mathrm{N} / \mathrm{P} \sim 3$. If the $\mathrm{N} / \mathrm{P}$ ratio $\geq 6$, the network is destroyed but the adsorption layer still contains complexes with DNA (Fig. 7), although the surface properties are primarily determined by the polyelectrolyte (Figs. 1, 3 and 4). Note that the formation of the network and equilibration of the microheterogeneous adsorption layer are slow processes that do not stop even when the surface tension reaches steady state values.

\section{Transferred films morphology}

Transfer of the adsorption layers from the liquid - gas interface onto mica surfaces by the Langmuir-Schäfer technique and the application of atomic force microscopy (AFM) gives additional information about the interfacial morphology. The adsorption layer of pure PDAHMAC consists of separate polydisperse compact aggregates at low concentrations $(\leq 15 \mu \mathrm{M})($ Fig. $8 \mathrm{a})$. At higher concentrations these aggregates can merge and form a continuous and inhomogeneous film with some holes corresponding to empty areas on the mica surface (Fig. 8b). This film is probably responsible for the relatively high dynamic surface elasticity of PDAHMAC solutions (Fig. 5). At even higher concentrations $(>75 \mu \mathrm{M})$ the holes disappear but the film remains strongly inhomogeneous and its thickness varies between 5 and $30 \mathrm{~nm}$ (Fig. 8c).

The morphology of mixed DNA/PDAHMAC adsorption layers at a low PDAHMAC concentration of $15 \mu \mathrm{M}$ is almost similar to that of pure PDAHMAC film and the layer consists mainly of separate polymer aggregates (Fig. 8d). Nevertheless, DNA certainly penetrates into the adsorption layer changing its dynamic properties at this concentration (Fig. 4). Probably the charge of DNA/PDAHMAC complexes at low concentrations is strongly negative and hinders their deposition on the negative mica surface. DNA appears in the adsorption layer transferred onto the mica surface only at higher concentrations $(\geq 30 \mu \mathrm{M})$ where one can observe long flexible threads 
consisting of DNA molecules complexed to some PDAHMAC molecules (Fig. 8e). These threads can form some separate patches of the DNA network or fill in the whole AFM image. The network can be rather loose or can consist of a large number of small cells, especially in the compressed adsorption layer (Fig. 8f). Some AFM images display a large number of intermixed relatively thick ribbons $(5-50 \mathrm{~nm})$, which probably also contain DNA chains together with PDAHMAC molecules (Fig. 8g).
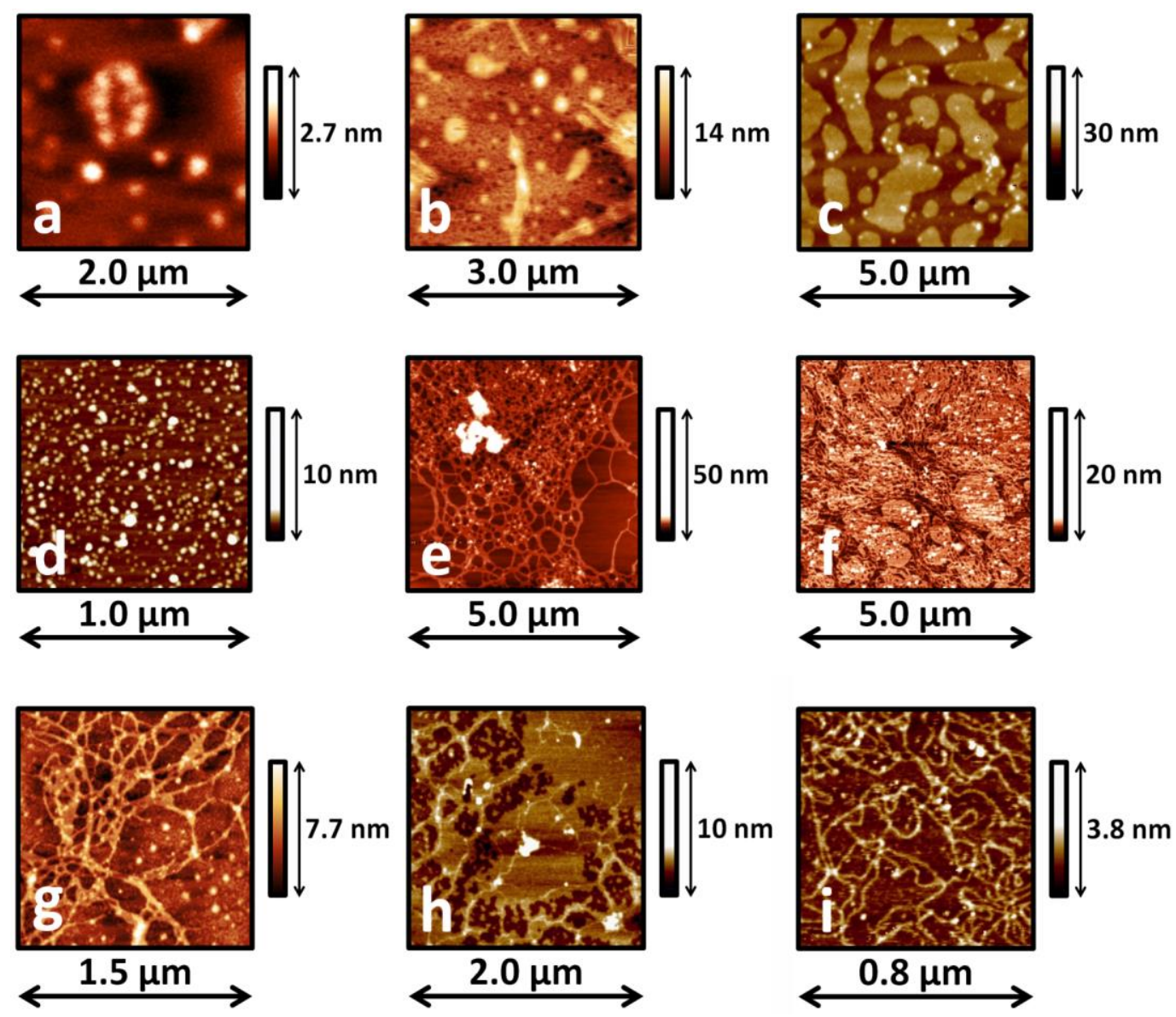

Figure 8. AFM images of PDAHMAC adsorption films at different concentrations: 15 (a), 75 (b) and 300 (c) $\mu \mathrm{M} ; \operatorname{DNA}(50 \mu \mathrm{M}) / \mathrm{PDAHMAC}$ adsorption films at different polyelectrolyte concentrations: 15 (d), 30 (e), 75 (f), 150 (g) and 500 (h) $\mu \mathrm{M}$; DNA(50 $\mu \mathrm{M}) /$ PDABMAC adsorption films at a polyelectrolyte concentration of $300 \mu \mathrm{M}$ (i). 
At high polymer concentrations $(500 \mu \mathrm{M})$ the surface properties of DNA(50 $\mu \mathrm{M}) / \mathrm{PDAHMAC}$ solutions are again close to those of pure PDAHMAC solutions (Figs. 1-5), but the AFM images still show some patches of a loose DNA network (Fig. 8h). In this case, most of the DNA molecules are displaced from the interface, DNA does not form a continuous network of interacting aggregates at the whole surface, and the surface properties are determined by adsorbed PDAHMAC molecules. Nevertheless, the DNA displacement is not complete, as the increase of DNA surface concentration in the course of twentyfold compression results in the recovery of a stable DNA network at high surface pressures (Fig. 6), and one can observe only very slow relaxation of the surface tension after compression (Fig. 7).

In terms of interfacial structures, the AFM images of the films transferred from the liquid - gas interface to mica did not reveal toroidal polyplexes of DNA/PDAHMAC, which are typical in the DNA/PDADMAC system at N/P ratios $>1 .^{29}$ Instead one can observe elongated DNA/PDAHMAC aggregates at all the investigated concentrations when the $\mathrm{N} / \mathrm{P}$ ratio $\geq 0.6$. Another question is related to the bulk structures that form in these mixed systems involving hydrophobically modified polyelectrolytes. We feel that it is unlikely that this distinction is connected with an increase of the number of hydrophobic groups in the polyelectrolytes as compared with PDADMAC. Application of dynamic light scattering allows observation of aggregate compaction at N/P ratios $>1$ in the system under investigation (Fig. S10 of the Supporting Information) but the AFM images (Fig. 8) do not. Moreover, the compact globular aggregates were also not observed in the surface layer of mixed solutions of DNA and cationic surfactants, ${ }^{28}$ although they are typical for the bulk phase of DNA/surfactant solutions. ${ }^{45-47}$ A possible explanation is that the surface activity of DNA/polyelectrolyte and DNA/surfactant aggregates decreases in the course of their folding because the local concentration of hydrophobic groups decreases in the outer shells of the globules. As a result, the aggregates are mainly adsorbed in the unfolded state. The subsequent compaction in 
the surface layer is not probable because it can lead to desorption of some of hydrophobic groups from the liquid surface and therefore is thermodynamically unfavorable. The folding of aggregates at the interface is also hampered by steric hindrances due to the high concentration of polyelectrolyte segments in the surface layer. At the same time, the adsorption of other unfolded DNA/polyelectrolyte aggregates close to the initially adsorbed ones is still possible, and their mutual interactions and the interactions with adsorbed polyelectrolyte molecules result finally in the formation of threadlike flexible aggregates. The application of structural bulk techniques such as small-angle neutron scattering, which is outside the scope of the present work, would be required to validate this inference.

\section{Tuning the polyelectrolyte hydrophobicity}

The obtained results show that the surface activity of DNA/PDAAMAC complexes depends strongly on the length of alkyl chain: the surface activity is close to zero for DNA/PDADMAC solutions but increases strongly for solutions of DNA/PDAHMAC due to a larger number of hydrophobic groups in the polymer. The complexes of DNA and poly(N,N-diallyl-N-butyl-Nmethylammonium chloride) (PDABMAC), which has shorter hydrophobic side chains than PDAHMAC, display intermediate surface activity compared with those of DNA/PDADMAC and DNA/PDAHMAC. While this observation is perhaps not unexpected, a comparison of the different systems studied reveals an interesting feature of the systems. The surface activity of PDABMAC is very low as the surface tension of a $300 \mu \mathrm{M}$ solution decreases only by $\sim 0.5 \mathrm{mN} / \mathrm{m}$ and the surface elasticity increases to about $2.5 \mathrm{mN} / \mathrm{m}$ over about 24 hours. For the mixed DNA(50 $\mu \mathrm{M}) / \mathrm{PDABMAC}(100 \mu \mathrm{M})$ solutions, the surface tension drops by $2.5 \mathrm{mN} / \mathrm{m}$ and the dynamic surface elasticity increases almost by an extra order of magnitude, up to $17 \mathrm{mN} / \mathrm{m}$ at the maximum, and decreases to about $10 \mathrm{mN} / \mathrm{m}$ at longer surface lifetimes (Figs. 9 and 10). Yet in the case of 
DNA/PDAHMAC solutions, the relative changes of the surface properties as compared to PDAHMAC solutions are not as strong (Figs. 1-5). This difference can be attributed to a strong synergistic effect of DNA and PDABMAC on the surface properties of their aqueous solutions.

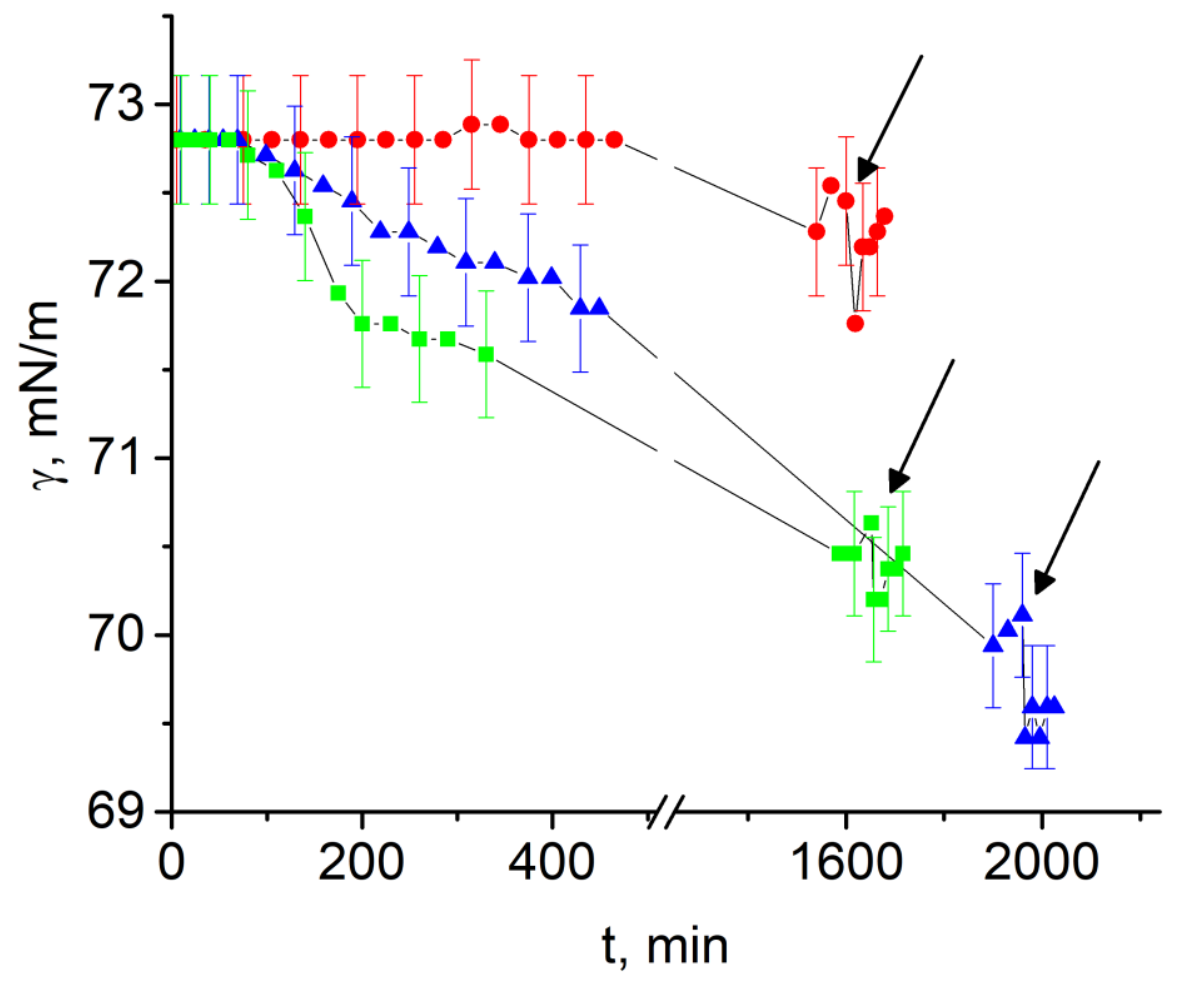

Figure 9. Kinetic dependencies of the surface tension of mixed DNA(50 $\mu \mathrm{M}) / \mathrm{PDABMAC}$ solutions at polyelectrolyte concentrations: 100 (green squares) and $300 \mu \mathrm{M}$ (blue triangles). Red circles correspond to a solution of pure PDABMAC with a concentration of $300 \mu \mathrm{M}$. Lines are guides for the eye. Arrows indicate the compression of the surface by $40 \%$.

Further, the ellipsometric results show a strong increase of the total adsorbed amount for a DNA/PDABMAC solution in comparison with the equivalent pure PDABMAC solution (Fig. 10 inset). The dynamic surface elasticity of $\sim 10 \mathrm{mN} / \mathrm{m}$ corresponds to the formation of an interfacial network of elongated DNA/PDABMAC aggregates (Figs. 8i and S11 of the Supporting 
Information), as in the case of DNA/PDAHMAC solutions (Fig. 8d-h). These results show that tuning the hydrophobicity of the polyelectrolyte can result in controlled interfacial morphologies of DNA/polyelectrolyte polyplexes at a fluid interface.

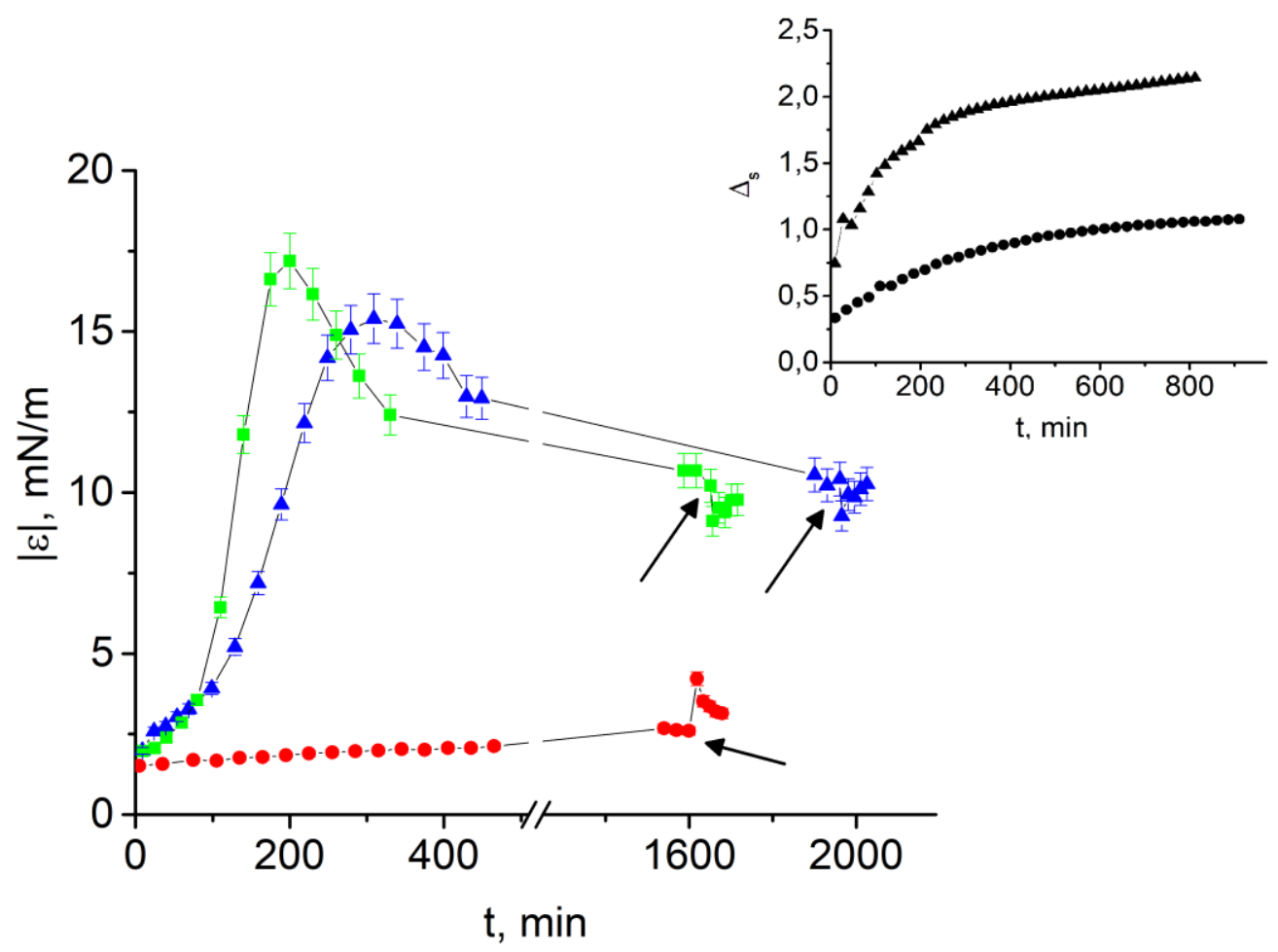

Figure 10. Kinetic dependencies of the dynamic surface elasticity of mixed DNA(50 $\mu \mathrm{M}$ )/PDABMAC solutions at polyelectrolyte concentrations: 100 (green squares) and $300 \mu \mathrm{M}$ (blue triangles). Red circles correspond to the solution of PDABMAC with concentration of $300 \mu \mathrm{M}$. Lines are guides for the eye. Arrows indicate the compression of the surface by $40 \%$. Inset: kinetic dependencies of the ellipsometric angle $\Delta_{\mathrm{s}}$ of PDABMAC solution (circles) and DNA(50 $\mu \mathrm{M}) / \mathrm{PDABMAC}$ solution (triangles) with a polyelectrolyte concentration of $300 \mu \mathrm{M}$.

\section{Conclusions}

In this work, we have applied surface tensiometry, ellipsometry and dilatational surface rheology to the liquid - gas interface of mixed solutions of DNA and hydrophobically modified cationic 
polyelectrolytes, we have used different experimental methodologies to optimize the range of information accessible, and we have applied AFM imaging to films transferred onto mica. The work has been carried out as a function of both the ratio of DNA to polyelectrolyte in the bulk of different samples and the surface age of individual samples, and with respect to the hydrophobicity of the polyelectrolyte through modifying the length of the side chains. To our knowledge, this is the first time such a study has been reported on the adsorption of DNA/polyelectrolyte polyplexes at the liquid - gas interface.

The adsorption layer properties depend strongly on the bulk composition of the samples. A rigid network of elongated DNA/polyelectrolyte complexes is present at the interface if the polyelectrolyte nitrogen to DNA phosphate molar ratios is between approximately 0.6 and 3 . These elongated structures are different from typical globular polyplexes, the distinction of which has been discussed in terms of a structural rearrangement at the interface: complexes maximize the number of hydrophobic groups in contact with the air to minimize the free energy of the system. As such, in addition to the influence of the water - air interface on the aggregation of DNA/polyelectrolyte complexes, the obtained results indicate polymorphism of the aggregates. The kinetic dependencies of the dynamic surface elasticity for these samples of relatively uncharged bulk complexes are non-monotonic and are qualitatively similar to those for solutions of pure polyelectrolytes, but the absolute values are much higher for the mixed solutions. The DNA/polyelectrolyte network at the interface is fragile and can break into pieces under mechanical perturbations of the solution surface. Also, the network formation is a relatively slow process compared with the fast adsorption of the complexes with low values of the absolute charge, which can be attributed to the lower concentration of surface-active complexes in bulk due to aggregation that is taking place in the bulk solution. 
If the polyelectrolyte nitrogen to DNA phosphate molar ratio is lower than about 0.6 or higher than about 3, the adsorption is slower, a rigid network is not formed and the surface properties are determined by the adsorbed polyelectrolyte. Even so, DNA/polyelectrolyte complexes have still been shown to be present in the adsorption layer as they exert a strong modification of the mechanical properties of the interface upon surface area compression and relaxation.

The results presented in this work demonstrate that tuning the hydrophobicity of polyelectrolytes for use in DNA-based polyplexes can be exploited to control the mechanical properties and morphology of adsorbed layers formed at hydrophobic fluid interfaces. While neutron scattering experiments were outside the scope of the present work, additional bulk and surface data on these systems in the future can help to extend the scope of these findings. This work provides a platform for extending the development of hydrophobically modified polyplexes in a range of applications from biomedicine to nanotechnology where interfacial interactions are all important.

\section{Supporting Information}

The following material is available online. Figures S1-S6: ${ }^{1} \mathrm{H}$ NMR spectra of poly(N,N-diallyl-Nalkyl-N-methylammonium chlorides) and corresponding monomers. Figure S7: Kinetic dependencies of the surface tension and the dynamic surface elasticity for mixed DNA(50 $\mu \mathrm{M}) /$ PDADMAC(300 $\mu \mathrm{M})$ solution. Figure S8: Dependence of the refractive index on the concentration of PDAHMAC solutions. Figure S9: $\zeta$ potential for mixed DNA(50 $\mu \mathrm{M}) / \mathrm{PDAHMAC}$ solutions with polyelectrolyte concentrations 15, 50, 75 and $300 \mu \mathrm{M}$. Figure S10: Size distribution for mixed DNA(50 $\mu \mathrm{M}) / \mathrm{PDAHMAC}$ solutions with polyelectrolyte concentrations 15,75 and 300 $\mu \mathrm{M}$. Figure S11: AFM image of a DNA(100 $\mu \mathrm{M}) /$ PDABMAC adsorption film at a polyelectrolyte concentration of $300 \mu \mathrm{M}$. Table S1: Rate constants for mixed DNA/PDAHMAC solutions derived from the kinetic dependencies of the ellipsometric angle $\Delta_{\mathrm{s}}$. 


\section{Acknowledgements}

This work was supported by the Russian Foundation of Basic Research, and the Ministry of Science and Technology of Taiwan (joint project no. 19-53-52006). The authors are grateful to the Centre for Diagnostics of Functional Materials for Medicine, Pharmacology and Nanoelectronics of $\mathrm{SPbGU}$ for the use of NTEGRA Prima setup, and the Centre for Innovative Technologies of Composite Nanomaterials of SPbGU for the use of laser diffraction equipment.

\section{Author contributions}

Conceptualization, B.A.N. and S.-Y.L; methodology, B.A.N., A.V.A. and P.S.V.; formal analysis, B.A.N. and P.S.V.; investigation, N.S.C, A.V.A. and K.A.T.; data curation, N.S.C, S.-Y.L. and K.A.T.; writing — original draft preparation, N.S.C. and R.A.C.; writing—review and editing, all authors; supervision, B.A.N.

\section{Conflict of interests}

The authors declare no conflict of interest.

\section{References}

(1) Laemmli, U. K. Characterization of DNA Condensates Induced by Poly(Ethylene Oxide) and Polylysine. Proc. Natl. Acad. Sci. U. S. A. 1975, 72 (11), 4288-4292.

(2) Marciel, A. B.; Chung, E. J.; Brettmann, B. K.; Leon, L. Bulk and Nanoscale Polypeptide Based Polyelectrolyte Complexes. Adv. Colloid Interface Sci. 2017, 239, 187-198.

(3) Jorge, A. F.; Nunes, S. C. C.; Cova, T. F. G. G.; Pais, A. A. C. C. Cooperative Action in DNA Condensation. Curr. Opin. Colloid Interface Sci. 2016, 26, 66-74.

(4) Zinchenko, A. DNA Conformational Behavior and Compaction in Biomimetic Systems: Toward Better Understanding of DNA Packaging in Cell. Adv. Colloid Interface Sci. 2016, 
$232,70-79$.

(5) Kasyanenko, N.; Dribinsky, B. Similarities and Differences in the Influence of Polycations and Oligomers on DNA Conformation and Packaging. Int. J. Biol. Macromol. 2016, 86, 216223.

(6) Vieregg, J. R.; Lueckheide, M.; Marciel, A. B.; Leon, L.; Bologna, A. J.; Rivera, J. R.; Tirrell, M. V. Oligonucleotide-Peptide Complexes: Phase Control by Hybridization. J. Am. Chem. Soc. 2018, 140 (5), 1632-1638.

(7) Thomas, T. J.; Thomas, T. Collapse of DNA in Packaging and Cellular Transport. Int. J. Biol. Macromol. 2018, 109, 36-48.

(8) Wang, Y.; Ye, M.; Xie, R.; Gong, S. Enhancing the in Vitro and in Vivo Stabilities of Polymeric Nucleic Acid Delivery Nanosystems. Bioconjug. Chem. 2019, 30 (2), 325-337.

(9) Unzueta, U.; Saccardo, P.; Domingo-Espín, J.; Cedano, J.; Conchillo-Solé, O.; GarcíaFruitós, E.; Céspedes, M. V.; Corchero, J. L.; Daura, X.; Mangues, R.; et al. Sheltering DNA in Self-Organizing, Protein-Only Nano-Shells as Artificial Viruses for Gene Delivery. Nanomedicine Nanotechnology, Biol. Med. 2014, 10 (3), 535-541.

(10) Bucki, R.; Janmey, P. A. Extracellular Aggregation of Polyelectrolytes Escaped from the Cell Interior: Mechanisms and Physiological Consequences. Curr. Opin. Colloid Interface Sci. 2016, 26, 84-89.

(11) Banani, S. F.; Lee, H. O.; Hyman, A. A.; Rosen, M. K. Biomolecular Condensates: Organizers of Cellular Biochemistry. Nat. Rev. Mol. Cell Biol. 2017, 18 (5), 285-298.

(12) Jain, A.; Vale, R. D. RNA Phase Transitions in Repeat Expansion Disorders. Nature 2017, 546 (7657), 243-247.

(13) Vieregg, J. R.; Tang, T. Y. D. Polynucleotides in Cellular Mimics: Coacervates and Lipid Vesicles. Curr. Opin. Colloid Interface Sci. 2016, 26, 50-57.

(14) Zhang, K.; Jiang, M.; Chen, D. DNA/Polymeric Micelle Self-Assembly Mimicking Chromatin Compaction. Angew. Chemie - Int. Ed. 2012, 51 (35), 8744-8747.

(15) Wang, W.; Zhang, K.; Chen, D. From Tunable DNA/Polymer Self-Assembly to Tailorable and Morphologically Pure Core-Shell Nanofibers. Langmuir 2018, 34 (50), 15350-15359.

(16) Pinto, M. F. V.; Morán, M. C.; Miguel, M. G.; Lindman, B.; Jurado, A. S.; Pais, A. A. C. C. Controlling the Morphology in DNA Condensation and Precipitation. Biomacromolecules 
2009, 10 (6), 1319-1323.

(17) Yang, P. W.; Lin, T. L.; Liu, I. T.; Hu, Y.; James, M. In Situ Neutron Reflectivity Studies of the Adsorption of DNA by Charged Diblock Copolymer Monolayers at the Air-Water Interface. Soft Matter 2012, 8 (27), 7161-7168.

(18) Paul, P. K.; Che, D. C.; Hiroyuki, K.; Araki, K.; Matsumoto, T. Adsorption Characteristics of Cytochrome c/DNA Complex Langmuir Molecular Assemblies at the Airwater Interface: A Surface Area-Normalized Isotherm Study. RSC Adv. 2017, 7 (60), 37755-37764.

(19) Stefaniu, C.; Brezesinski, G.; Möhwald, H. Langmuir Monolayers as Models to Study Processes at Membrane Surfaces. Adv. Colloid Interface Sci. 2014, 208, 197-213.

(20) Caseli, L.; Nobre, T. M.; Ramos, A. P.; Monteiro, D. S.; Zaniquelli, M. E. D. The Role of Langmuir Monolayers to Understand Biological Events. ACS Symp. Ser. 2015, 1215, 65-88.

(21) Noskov, B. A. Protein Conformational Transitions at the Liquid-Gas Interface as Studied by Dilational Surface Rheology. Adv. Colloid Interface Sci. 2014, 206, 222-238.

(22) Campioni, S.; Carret, G.; Jordens, S.; Nicoud, L.; Mezzenga, R.; Riek, R. The Presence of an Air-Water Interface Affects Formation and Elongation of $\alpha$-Synuclein Fibrils. J. Am. Chem. Soc. 2014, 136 (7), 2866-2875.

(23) Dabkowska, A. P.; Barlow, D. J.; Campbell, R. A.; Hughes, A. V.; Quinn, P. J.; Lawrence, M. J. Effect of Helper Lipids on the Interaction of DNA with Cationic Lipid Monolayers Studied by Specular Neutron Reflection. Biomacromolecules 2012, 13 (8), 2391-2401.

(24) Lee, J.; Chang, C. H. The Interaction between the Outer Layer of a Mixed Ion Pair Amphiphile/Double-Chained Cationic Surfactant Vesicle and DNA: A Langmuir Monolayer Study. Soft Matter 2014, 10 (11), 1831-1839.

(25) Janich, C.; Hädicke, A.; Bakowsky, U.; Brezesinski, G.; Wölk, C. Interaction of DNA with Cationic Lipid Mixtures - Investigation at Langmuir Lipid Monolayers. Langmuir 2017, 33 (39), 10172-10183.

(26) Zhang, J.; Taylor, D. J. F.; Li, P. X.; Thomas, R. K.; Wang, J. B.; Penfold, J. B. Adsorption of DNA and Dodecyl Trimethylammonium Bromide Mixtures at the Air/Water Interface: A Neutron Reflectometry Study. Langmuir 2008, 24 (5), 1863-1872.

(27) Kundu, S.; Langevin, D.; Lee, L. T. Neutron Reflectivity Study of the Complexation of DNA with Lipids and Surfactants at the Surface of Water. Langmuir 2008, 24 (21), 12347-12353. 
(28) Lyadinskaya, V. V.; Lin, S. Y.; Michailov, A. V.; Povolotskiy, A. V.; Noskov, B. A. Phase Transitions in DNA/Surfactant Adsorption Layers. Langmuir 2016, 32 (50), 13435-13445.

(29) Alatorre-Meda, M.; Taboada, P.; Krajewska, B.; Willemeit, M.; Deml, A.; Klösel, R.; Rodríguez, J. R. DNA-Poly(Diallyldimethylammonium Chloride) Complexation and Transfection Efficiency. J. Phys. Chem. B 2010, 114 (29), 9356-9366.

(30) Grueso, E.; Kuliszewska, E.; Roldan, E.; Perez-Tejeda, P.; Prado-Gotor, R.; Brecker, L. DNA Conformational Changes Induced by Cationic Gemini Surfactants: The Key to Switching DNA Compact Structures into Elongated Forms. RSC Adv. 2015, 5 (37), 2943329446.

(31) Novikova, A. A.; Vlasov, P. S.; Lin, S. Y.; Sedláková, Z.; Noskov, B. A. Dynamic Surface Properties of Poly(Methylalkyldiallylammonium Chloride) Solutions. J. Taiwan Inst. Chem. Eng. 2017, 80, 122-127.

(32) Tsvetkov, N. V.; Lezov, A. A.; Vlasov, P. S.; Lezova, A. A.; Samokhvalova, S. A.;

Lebedeva, E. V.; Polushina, G. E. Copolymers of Diallyldimethylammonium Chloride and 2(Diallyl(Methyl) Ammonio) Acetate: Effect of Composition and Ionic Strength on Conformational Properties. Eur. Polym. J. 2016, 84, 268-278.

(33) Pegram, L. M.; Wendorff, T.; Erdmann, R.; Shkel, I.; Bellissimo, D.; Felitsky, D. J.; Record, M. T. Why Hofmeister Effects of Many Salts Favor Protein Folding but Not DNA Helix Formation. Proc. Natl. Acad. Sci. U. S. A. 2010, 107 (17), 7716-7721.

(34) Noskov, B. A.; Akentiev, A. V.; Bilibin, A. Y.; Zorin, I. M.; Miller, R. Dilational Surface Viscoelasticity of Polymer Solutions. Adv. Colloid Interface Sci. 2003, 104 (1-3), 245-271.

(35) Harke, M.; Teppner, R.; Schulz, O.; Motschmann, H.; Orendi, H. Description of a Single Modular Optical Setup for Ellipsometry, Surface Plasmons, Waveguide Modes, and Their Corresponding Imaging Techniques Including Brewster Angle Microscopy. Rev. Sci. Instrum. 1997, 68 (8), 3130-3134.

(36) Campbell, R. A.; Yanez Arteta, M.; Angus-Smyth, A.; Nylander, T.; Noskov, B. A.; Varga, I. Direct Impact of Nonequilibrium Aggregates on the Structure and Morphology of Pdadmac/SDS Layers at the Air/Water Interface. Langmuir 2014, 30 (29), 8664-8674.

(37) Langmuir, I.; Schaefer, V. J. Activities of Urease and Pepsin Monolayers. J. Am. Chem. Soc. 1938, 60 (6), 1351-1360. 
(38) Noskov, B. A.; Bilibin, A. Y.; Lezov, A. V.; Loglio, G.; Filippov, S. K.; Zorin, I. M.; Miller, R. Dynamic Surface Elasticity of Polyelectrolyte Solutions. Colloids Surfaces A Physicochem. Eng. Asp. 2007, 298 (1-2), 115-122.

(39) Elhadj, S.; Singh, G.; Saraf, R. F. Optical Properties of an Immobilized DNA Monolayer from 255 to $700 \mathrm{Nm}$. Langmuir 2004, 20 (13), 5539-5543.

(40) Varga, I.; Campbell, R. A. General Physical Description of the Behavior of Oppositely Charged Polyelectrolyte/Surfactant Mixtures at the Air/Water Interface. Langmuir 2017, 33 (23), 5915-5924.

(41) Tummino, A.; Toscano, J.; Sebastiani, F.; Noskov, B. A.; Varga, I.; Campbell, R. A. Effects of Aggregate Charge and Subphase Ionic Strength on the Properties of Spread Polyelectrolyte/Surfactant Films at the Air/Water Interface under Static and Dynamic Conditions. Langmuir 2018, 34 (6), 2312-2323.

(42) Noskov, B. A. Dilational Surface Rheology of Polymer and Polymer/Surfactant Solutions. Curr. Opin. Colloid Interface Sci. 2010, 15 (4), 229-236.

(43) Noskov, B. A.; Timoshen, K. A.; Akentiev, A. V.; Chirkov, N. S.; Dubovsky, I. M.; Lebedev, V. T.; Lin, S. Y.; Loglio, G.; Miller, R.; Sedov, V. P.; et al. Dynamic Surface Properties of Fullerenol Solutions. Langmuir 2019, 35 (10), 3773-3779.

(44) Yazhgur, P. A.; Noskov, B. A.; Liggieri, L.; Lin, S. Y.; Loglio, G.; Miller, R.; Ravera, F. Dynamic Properties of Mixed Nanoparticle/Surfactant Adsorption Layers. Soft Matter 2013, 9 (12), 3305-3314.

(45) Miguel, M. G.; Pais, A. A. C. C.; Dias, R. S.; Leal, C.; Rosa, M.; Lindman, B. DNA-Cationic Amphiphile Interactions. Colloids Surfaces A Physicochem. Eng. Asp. 2003, 228 (1-3), 4355.

(46) Dias, R. S.; Pais, A. A. C. C.; Miguel, M. G.; Lindman, B. DNA and Surfactants in Bulk and at Interfaces. Colloids Surfaces A Physicochem. Eng. Asp. 2004, 250 (1-3 SPEC. ISS.), 115131.

(47) Cárdenas, M.; Dreiss, C. A.; Nylander, T.; Chan, C. P.; Cosgrove, T.; Lindman, B. SANS Study of the Interactions among DNA, a Cationic Surfactant, and Polystyrene Latex Particles. Langmuir 2005, 21 (8), 3578-3583. 
Graphic abstract

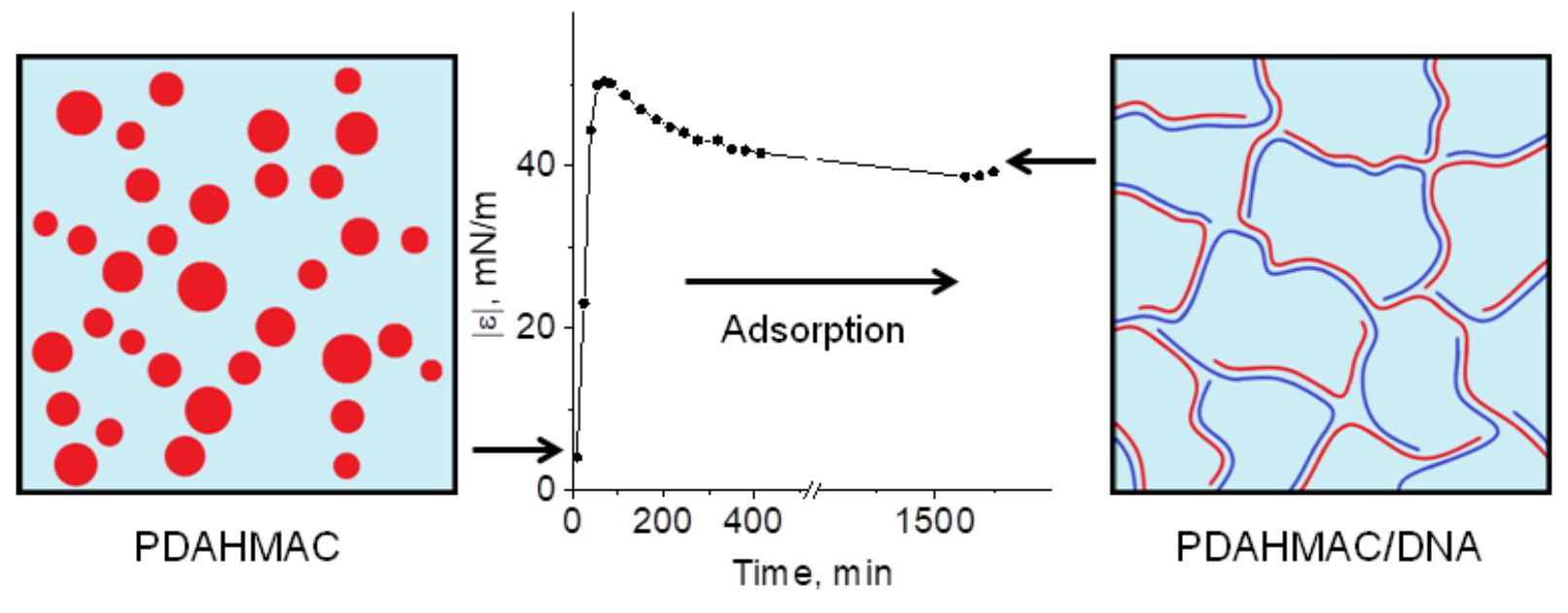

